\title{
Título da página eletrónica: Arterial Network
}

URL: http://www.arterialnetwork.org/

\section{Claudino Ferreira}

\section{(2) OpenEdition \\ Journals}

Edição electrónica

URL: http://journals.openedition.org/rccs/5184

DOI: $10.4000 /$ rccs. 5184

ISSN: 2182-7435

\section{Editora}

Centro de Estudos Sociais da Universidade de Coimbra

Edição impressa

Data de publição: 1 dezembro 2012

Paginação: 218-220

ISSN: 0254-1106

Refêrencia eletrónica

Claudino Ferreira, «Título da página eletrónica: Arterial Network », Revista Crítica de Ciências Sociais [Online], 99 | 2012, posto online no dia 04 setembro 2013, consultado o 22 setembro 2020. URL http://journals.openedition.org/rccs/5184; DOI : https://doi.org/10.4000/rccs.5184 


\section{Espaço Virtual}

\section{Título da página eletrónica: Creative Cities Network URL: http://www.unesco.org/new/en/culture/themes/creativity/creative- -industries/creative-cities-network/}

Há muito que a Unesco se interessa pelas questões urbanas. Por isso, não é de estranhar que o tema das "cidades criativas", que casa questões urbanas com questões culturais caras à organização, tenha levado a Unesco a constituir uma Rede de Cidades Criativas.

Ao constituir esta rede, a Unesco reconhece o protagonismo crescente das cidades, mas também a importância que a cultura e as atividades culturais desempenham atualmente, e de forma crescente, na dinamização e transformação urbanas. Por outro lado, como a própria Unesco justifica ao explicar as razões que levaram à criação desta rede, não deixa de ser relevante o facto de a questão da criatividade animar crescentemente as agendas políticas locais e nacionais e de ser vista como um elemento central das estratégias de desenvolvimento económico. Acresce que a Unesco tem estado, nas últimas décadas, particularmente ativa no domínio da criação e sustentação de redes, reconhecendo, neste caso, que uma rede de cidades criativas é importante na exata medida em que as indústrias criativas constituem hoje a base da estrutura social de muitas cidades, reforçando a diversidade cultural, estimulando a vida quotidiana e contribuindo para a consolidação da identidade local e da autoestima.
A Rede das Cidades Criativas resultou da iniciativa "Aliança global em prol da diversidade cultural”, lançada pela Unesco em 2004. ${ }^{1}$ Em termos gerais, a Rede constitui-se para promover a diversidade cultural e o desenvolvimento urbano sustentável. Aposta, especificamente, no desenvolvimento da cooperação internacional entre cidades, promovendo a constituição de parcerias para o desenvolvimento no contexto das prioridades globais estabelecidas pela Unesco: "cultura e desenvolvimento" e "desenvolvimento sustentável". As noções de "economia criativa" e "turismo criativo" fundamentam e orientam a existência da Rede, procurando funcionar como eixos estruturantes das ações desenvolvidas no âmbito das parcerias. Estas, disseminando-se por várias áreas da cultura, visam promover a partilha de experiências e contribuir para a emergência de novas oportunidades de cooperação numa base mundial. As cidades podem aderir à Rede, seja enquanto "centros criativos", seja enquanto "agrupamentos socioculturais". Os centros criativos orientam-se para a promoção do desenvolvimento socioeconómico e cultural, quer nos países desenvolvidos, quer nos países em vias de desenvolvimento, através das indústrias criativas. Os agrupamentos socioculturais pretendem reforçar as relações

\footnotetext{
${ }^{1}$ A "Aliança global em prol da diversidade cultural" visa promover a constituição de parcerias, no domínio das indústrias culturais, entre atores privados, atores públicos e sociedade civil. Trata-se de uma medida operativa da "Convenção para a proteção e promoção da diversidade de expressões culturais". No site desta iniciativa podem ser encontradas ferramentas metodológicas que ajudam a concretizar e a reforçar parcerias na área da cultura.
} 
entre comunidades diferenciadas, no domínio sociocultural, de modo a criar ambientes urbanos equilibrados.

São 34 as cidades que integram atualmente a Rede das Cidades Criativas, repartindo-se pelas 7 áreas das indústrias criativas fixadas pela Unesco: literatura, cinema, música, artesanato e artes populares, design, artes numéricas e gastronomia. Design, com 11 cidades aderentes, é a área que reúne maior número de membros. Artes numéricas, com um único membro, é a área menos participada. Entre os membros da Rede contam-se grandes cidades, como Pequim (design), Kobe (design), Shangai (design), Seoul (design); cidades médias, como Lyon (artes numéricas), Sydney (cinema), Buenos Aires (design), Berlim (design); e cidades de menor dimensão, como Edimburgo (literatura), Dublin (literatura), Reykjavik (literatura), Sevilha (música), Bolonha (música). Não há, neste conjunto de cidades, nenhuma que seja originária do universo da lusofonia. Não obstante esta diversidade, a Rede tem um manifesto problema de densidade, havendo áreas, como, por exemplo, artes numéricas e cinema, em que o número de cidades aderentes nem sequer cauciona $\mathrm{o}$ princípio da parceria.

O site da Rede disponibiliza formulário e informações de submissão de candidatura. Os procedimentos necessários não deixam de ser um fator de entrave à candidatura e adesão de novas cidades. Em primeiro lugar, a adesão à Rede depende de um filtro político, uma vez que é necessária a autorização do Presidente da Câmara local (ou equivalente). Existindo a missiva oficial de concordância, a cidade submete a candidatura à Unesco. Em seguida, a Unesco confere se a Comissão Nacional da Unesco correspondente reconhece e apoia a candidatura, condição que, na prática, é obrigatória, para o sucesso da candidatura. Segue-se a avaliação por um grupo de peritos externo, constituído por especialistas de ONGs na área de candidatura. Finalmente, sob recomendação do grupo de peritos, o Diretor Geral da Unesco toma uma decisão final. Ainda que o processo pareça simples e linear, a verdade é que ele é bem mais complexo que aquilo que aparenta ser. O formulário de candidatura obriga, não apenas a uma apresentação detalhada da cidade, que mostre tratar-se de um candidato ideal para integrar a área criativa a que se candidata, mas exige, igualmente, que a candidatura demonstre que a cidade tem algo de concreto para oferecer e que seja materializada e concretizada a disposição para cooperar com outras cidades. A Unesco exige, por outro lado, que o dossier de candidatura resulte do trabalho de um comité de gestão misto, composto por membros do setor privado, do setor público e da sociedade civil. Com anexos, e a obrigatoriedade de ser redigido em língua inglesa ou francesa, o dossier de candidatura deve incluir 50 a 80 páginas.

Procurando estimular iniciativas no âmbito da Rede, o site divulga algumas oportunidades, tais como o "Fundo Internacional para a promoção da cultura" e as bolsas para artistas Unesco-Aschberg. Todavia, estes recursos têm um alcance muito limitado em termos de atratividade para cidades que equacionem fazer parte da Rede. A Rede organiza e associa-se ainda a alguns eventos e publicações, que podem ser consultados na página (se bem que algumas das publicações tenham um alcance comercial). Para uma rede que tem a ambição declarada de criar novas oportunidades de cooperação entre cidades, lançar produtos culturais diversos nos mercados, ou cultivar a inovação através de trocas de saberes-fazeres, os resultados têm sido, na verdade, muito limitados. 


\section{Título da página eletrónica: Criaticidades - Cidades criativas no Brasil URL: http://www.criaticidades.com.br/}

Criaticidades é um exemplo concreto, no universo da lusofonia, que demonstra a tendência para que a economia criativa se torne uma área de negócio, onde emergem serviços especializados e diversificados. Criaticidades presta alguns desses serviços.

Trata-se de um projeto empresarial, desenvolvido pela "Garimpo de Soluções" e pela "Umana", que procura identificar oportunidades e fornecer serviços que permitam que o setor da economia criativa contribua para o desenvolvimento socioeconómico das cidades brasileiras. O projeto estende-se por 5 linhas que apresentam e discutem o conceito de economia criativa, enquadrando essa discussão em apresentação de casos e entrevistas a especialistas, não só brasileiros mas também de relevância mundial.

Baseado numa estrutura simples e intuitiva, de navegação fácil, o site estrutura-se em 5 linhas: economia criativa, onde se discute o conceito, a sua emergência e a sua apropriação pelos organismos governamentais na Inglaterra e no Brasil; cidade criativa, onde se equacionam vias para assegurar a sustentabilidade e incrementar a criatividade nas cidades; setores criativos, onde se revela como setores da economia brasileira, designadamente nos domínios da moda e do design, se apropriam e exploram as ideias de criatividade, projetando produtos artesanais; empreendedorismo, onde se dá espaço aos empreendedores criativos, apresentando-se casos bem-sucedidos em várias áreas da economia brasileira, tanto no Brasil como no exterior; Paraty e Paulínia, onde se explica como as duas cidades, a primeira do Estado do Rio de Janeiro e a segunda do Estado de São Paulo, se converteram em exemplos de inovação no setor cultural, designadamente em termos de parcerias público-privadas.

Partindo de uma exposição concisa e fácil de incorporar, o conceito é explicitado a partir de 3 dimensões: indústrias criativas, relevando-se aqui o facto de a sua definição ser variável e sempre relativa a fatores contextuais, como, por exemplo, a vocação e as potencialidades da região em que essas indústrias operam; economia criativa, que salienta o impacto dos bens e serviços disponibilizados pelas indústrias criativas nos setores económicos em que se inserem, assim como as relações entre indústrias criativas e setores económicos (impacto da moda no têxtil, impacto da arquitetura na construção civil, etc.); cidades e espaços criativos, destacando-se as potencialidades das ligações entre setores (económico, cultural, urbanístico, turístico, etc.) no domínio da valorização das singularidades locais e do efeito que isso pode ter em termos de inovação.

O site disponibiliza uma coluna de notícias, que permite um amplo grau de cobertura sobre as iniciativas que emergem no Brasil sobre indústrias criativas e cidades criativas. Todavia, umas das áreas de maior relevância do Criaticidades são as entrevistas a personalidades que trabalham na área das cidades criativas. Estas entrevistas, suficientemente breves para vincarem mensagens fortes, são apresentadas de forma atrativa, em vídeo, sendo feitas a personalidades relevantes na área e legendadas sempre que os protagonistas não falam português. Podem ser vistas por categoria (casos concretos, economia criativa, empreendedorismo, urbanismo, economia e sustentabilidade), o que facilita a legibilidade e $\mathrm{o}$ acesso. $\mathrm{O}$ site promove $\mathrm{o}$ "Manifesto São Paulo Criativa", uma petição online, que visa promover São Paulo 
e as demais cidades do Estado à condição de cidades criativas.

A Garimpo de Soluções, uma das empresas responsáveis pelo Criaticidades é uma empresa que disponibiliza serviços no domínio de atuação da economia criativa e das cidades criativas. Criaticidades procura agregar, apresentando-os sumariamente, os serviços de consultoria prestados a empresas privadas, governos e à ONU. Além da assessoria, a empresa providencia: palestras em cinco idiomas; organização e edição de estudos e livros pioneiros; missões internacionais; e curadoria de seminários, cursos e oficinas. A secção "Livros" do site da empresa (http://garimpodesolucoes. com.br/) referencia as principais publicações não periódicas sobre economia criativa em língua portuguesa, em particular as que se referem ao Brasil. A Umana (http://www.umana.com.br), a segunda empresa responsável pelo Criaticidades, produz projetos de comunicação, designadamente audiovisuais.

Criaticidades dispõe de um "comité criativo" multidisciplinar, constituído por diversas personalidades com experiência na área que coordenam, que se estende por 13 áreas: literatura, empreendedorismo, políticas públicas, sustentabilidade, processos culturais, arquitetura e urbanismo, economia criativa, teatro, médias digitais, gastronomia, design, turismo e património cultural.

Paulo Peixoto

\section{Título da página eletrónica: Arterial Network URL: http://www.arterialnetwork.org/}

A Arterial Network é, nas palavras da própria organização, uma "rede dinâmica de indivíduos, organizações, apoiantes, empresas e instituições empenhadas no setor cultural e criativo africano". A organização teve origem no congresso Revitalising Africa's Cultural Assets, realizado em Goree Island em 2007, que juntou organizações não governamentais, empresas das indústrias criativas, festivais e artistas em torno do debate sobre a situação e as perspetivas da cultura e do setor criativo no continente Africano. Em 2009, no segundo encontro, realizado em Joanesburgo, os participantes, oriundos de 28 países africanos, decidiram dar um enquadramento mais formal à rede, o que conduziu à adoção de uma Constituição, em 2011, que estabelece os objetivos, a estrutura organizacional e o modo de funcionamento da rede.

A Arterial Network é hoje uma extensa rede que integra participantes de 40 países africanos. Formalizada como uma organização sem fins lucrativos, assume-se como uma organização da sociedade civil, aberta à participação de todos os indivíduos e entidades não governamentais com atuação ou interesse no setor cultural e criativo. Tendo o seu Secretariado Geral sediado em Cape Town, estrutura-se como uma rede de redes nacionais, existindo por isso delegações e representações nacionais nos vários países africanos integrantes.

$\mathrm{Na}$ Constituição, acessível a partir da página eletrónica, a Arterial Network define-se como uma rede do "setor criativo da sociedade civil africana empenhada nas artes, de uma maneira que visa contribuir para o desenvolvimento, os direitos humanos, a democracia e a erradicação da pobreza no continente africano." Merece especial referência a existência de uma equipa de missão para as políticas culturais no continente africano, que se propõe "desenvolver posições da Arterial Network 
a respeito de assuntos relacionados com as políticas culturais, assim como apoiar peritos que possam representar as perspetivas da sociedade civil nesse domínio em fóruns locais e globais."

Entre as atividades promovidas pela Arterial Network, destaca-se a African Creative Economy Conference (ACE), um encontro de grande dimensão e impacto que se realiza anualmente desde 2011. Depois das edições de 2011 em Nairobi e 2012 em Dakar, a edição de 2013 realiza-se em outubro em Cape Town. O programa inclui, para além de sessões de debate em torno de temas diretamente relacionados com o estado das artes e do setor criativo e o seu papel para o desenvolvimento do continente, uma vasta programação cultural, constituída por eventos artísticos que apresentarão uma mostra da atividade criativa africana em domínios como o teatro, cinema, música, literatura, moda, gastronomia e artesanato.

A página eletrónica da Arterial Network, para lá de dar conta da história, da estrutura e das atividades da rede, inclui uma série de outros recursos e informações de grande utilidade para aceder ao universo das artes e do setor criativo no continente africano. É assim uma página de grande relevo tanto para profissionais e organizações artísticas e culturais, como para amantes e interessados nas artes e atividades criativas africanas, como ainda para estudiosos do setor no continente. Nela podemos encontrar notícias sobre a atividade cultural e criativa no continente e nos vários países que integram a rede, informação sobre projetos de tipos variados, em curso ou em surgimento no setor, ofertas de empregos e de oportunidades, links para iniciativas e eventos de caráter cultural, criativo, académico e científico. O blogue da Arterial Network, acessível a partir da página principal, constitui por seu turno um interessante espaço de reflexão, troca de opinião e difusão de informação sobre a atividade cultural e criativa em África. É possível igualmente subscrever uma newsletter, que divulga regularmente o mesmo tipo de informação que se encontra na página eletrónica e no blogue. A rede está também presente no facebook e no twitter.

Claudino Ferreira 
